\title{
Reduced selective learning in patients with fibromyalgia vs healthy controls
}

Citation for published version (APA):

Meulders, A., Boddez, Y., Blanco, F., Van Den Houte, M., \& Vlaeyen, J. W. S. (2018). Reduced selective learning in patients with fibromyalgia vs healthy controls. Pain, 159(7), 1268-1276. https://doi.org/10.1097/j.pain.0000000000001207

Document status and date:

Published: 01/07/2018

DOI:

10.1097/j.pain.0000000000001207

Document Version:

Publisher's PDF, also known as Version of record

Document license:

Taverne

\section{Please check the document version of this publication:}

- A submitted manuscript is the version of the article upon submission and before peer-review. There can be important differences between the submitted version and the official published version of record.

People interested in the research are advised to contact the author for the final version of the publication, or visit the DOI to the publisher's website.

- The final author version and the galley proof are versions of the publication after peer review.

- The final published version features the final layout of the paper including the volume, issue and page numbers.

Link to publication

\footnotetext{
General rights rights.

- You may freely distribute the URL identifying the publication in the public portal. please follow below link for the End User Agreement:

www.umlib.nl/taverne-license

Take down policy

If you believe that this document breaches copyright please contact us at:

repository@maastrichtuniversity.nl

providing details and we will investigate your claim.
}

Copyright and moral rights for the publications made accessible in the public portal are retained by the authors and/or other copyright owners and it is a condition of accessing publications that users recognise and abide by the legal requirements associated with these

- Users may download and print one copy of any publication from the public portal for the purpose of private study or research.

- You may not further distribute the material or use it for any profit-making activity or commercial gain

If the publication is distributed under the terms of Article $25 \mathrm{fa}$ of the Dutch Copyright Act, indicated by the "Taverne" license above, 


\title{
Reduced selective learning in patients with fibromyalgia vs healthy controls
}

\author{
Ann Meulders ${ }^{\mathrm{a}, \mathrm{b}, \mathrm{c}, \star}$, Yannick Boddez $^{\mathrm{b}, \mathrm{d}, \mathrm{e}}$, Fernando Blanco ${ }^{\dagger}$, Maaike Van Den Houte ${ }^{\mathrm{a}, \mathrm{b}}$, Johan W.S. Vlaeyen ${ }^{\mathrm{a}, \mathrm{b}, \mathrm{c}}$
}

\begin{abstract}
Impaired selective fear learning has been advanced as a core mechanism involved in excessive spreading of protective responses such as pain-related fear and avoidance leading to disability in chronic pain conditions. Using the litmus test for selective learning effects, the blocking procedure, we tested the hypothesis that patients with fibromyalgia (FM) show less selective threat learning than healthy controls (HCs). We introduce a novel selective learning task based around a clinical diary scenario. On a trial-by-trial basis, participants rated whether they expected certain situations ( $A, B, Z$, and $X$ ) in the diary of a fictive FM patient would trigger pain in that patient. The procedure did not involve any experimental pain induction because the verbal outcomes "pain" or "no pain" were used. During the elemental acquisition phase, one situation was followed by "pain" (A+, eg, "Kim slept badly, and reports pain"), whereas another situation was followed by "no pain" (Z-, eg, "Kim was stressed, and reports no pain"). During the compound acquisition phase, another situation $(X)$, referred to as the blocked stimulus, was presented in compound with a previously pain-eliciting situation and also paired with "pain" (AX+, eg, Kim slept badly" and "Kim has vacuumed," and reports pain). Simultaneously, a novel situation was introduced and also followed by "pain" (B+). Within-group comparisons showed blocking (ie, significant difference between B and $\mathrm{X}$ ) in the HCs, but not in the patients with FM. This study is the first in directly assessing differences in selective learning between patients with FM and HCs using a blocking procedure.
\end{abstract}

Keywords: Blocking, Stimulus competition, Causal learning, Fibromyalgia, Pain expectancy, Chronic pain

\section{Introduction}

Pain serves a vital alarm function: the accurate prediction of when and where in the body pain occurs promotes survival, as it drives appropriate action in protecting against bodily threat. ${ }^{39}$ Pavlovian conditioning is the critical mechanism underlying the prediction of the occurrence of potentially harmful stimuli in the environment. ${ }^{28-30}$ More specifically, when a stimulus (conditioned stimulus [CS]) has previously been paired with pain (unconditioned stimulus [US]), this stimulus in itself may eventually elicit fear and prompt avoidance behavior (conditioned response). ${ }^{27}$ Because multiple external, internal, and proprioceptive indicators may cooccur with a pain episode, identifying

\footnotetext{
Sponsorships or competing interests that may be relevant to content are disclosed at the end of this article.

${ }^{a}$ Research Group Health Psychology, KU Leuven, Leuven, Belgium, ${ }^{b}$ Center for Excellence Generalization on Research in Health and Psychopathology, KU Leuven, Leuven, Belgium, ${ }^{c}$ Department of Clinical Psychological Science, Research Group Behavioral Medicine, Maastricht University, the Netherlands, ${ }^{d}$ Department of Clinical Psychology, University of Groningen, Groningen, the Netherlands, ${ }^{e}$ Center for the Psychology of Learning and Experimental Psychopathology, KU Leuven, Leuven, Belgium, ${ }^{f}$ Laboratory of Experimental Psychology, University of Deusto, Bilbao, Spain

${ }^{*}$ Corresponding author. Address: Department of Psychology, KU Leuven, Tiensestraat 102, Box 3726, 3000 Leuven, Belgium. Tel.: + 32 (0)16 3260 38; fax: +32 (0)16 3261 44. E-mail address: ann.meulders@kuleuven.be (A. Meulders).
}

Supplemental digital content is available for this article. Direct URL citations appear in the printed text and are provided in the HTML and PDF versions of this article on the journal's Web site (www. painjournalonline.com).

PAIN 159 (2018) 1268-1276

(C) 2018 International Association for the Study of Pain

http://dx.doi.org/10.1097/j.pain.0000000000001207 discriminate predictors of pain among all these stimuli is challenging. Failure to pinpoint actual predictors of pain can lead to the spreading of fear to other stimuli that cooccurred with the pain episode, resulting in persistent anxiety and avoidance behavior. ${ }^{6,14,26,37}$ For example, if someone experiences a shooting pain when getting out of bed, this person may not only attribute the pain to the specific stretching movement actually causing the pain, but also to having slept badly or even to the strenuous exercise the day before.

One possible mechanism explaining the maladaptive spreading of protective responses is impaired selective threat learning. Accumulating evidence shows that individuals suffering from chronic pain display impaired differential learning and excessive generalization in differential conditioning paradigms and generalization protocols, ${ }^{15,23-25}$ both suggesting a lack of selectivity. The most clear-cut way to investigate selective learning effects in the laboratory, however, is the blocking procedure. ${ }^{7,17}$ In a blocking procedure, 1 event $(A+)$ is paired with pain (US) in a first stage. Another event $(X)$, referred to as the blocked stimulus, presented in compound with the original pain-eliciting event is also paired with pain in a second stage $(A X+)$. During the crucial test of $X$ alone, fear responding is typically weak or blocked, despite the previous pairing with the pain. However, individual differences in the magnitude of the blocking effect exist. For example, Boddez et al. ${ }^{3}$ demonstrated that high trait anxiety scores in a subclinical sample were associated with elevated USexpectancy for the blocked stimulus $(X)$, indicating impaired selectivity in the learning of associations between events.

Because it is commonly acknowledged that the conditions for causal learning (ie, relationship between 2 neutral events) are very similar to those underlying Pavlovian conditioning (with a biologically relevant US), 2,9,33 we developed a pain-relevant 
selective learning task, using a clinical diary scenario. Participants rated on a trial-by-trial basis whether they expected that certain situations in the diary of a fictive fibromyalgia (FM) patient would trigger pain in that patient. They received feedback in the format of the verbal outcome "pain" or "no pain." Assessing pain expectancy judgments to these scenarios enabled us to evaluate selective learning without experimentally inducing pain or worsening patients' symptoms. Based on previous research showing excessive generalization in people with chronic pain, suggesting a lack of selective learning, we hypothesized that patients with FM would show less blocking than healthy controls (HCs).

\section{Materials and methods}

\subsection{Participants}

A convenience sample of 27 patients with FM (26 females, mean $\pm \mathrm{SD}$ age $=46 \pm 9$ years), and 27 age-matched healthy, painfree controls (mean \pm SD age $=48 \pm 9$ years) participated in the study. Five-year ranges were used to match HCs to patients. ${ }^{24}$ Patients with FM had a doctor-based diagnosis of FM satisfying the American College of Rheumatology new diagnostic criteria for $\mathrm{FM}^{43}$ and experienced substantial reductions in daily life functioning caused by this condition. The inclusion criterion for the $\mathrm{HC}$ group was to not have FM. Patients with FM and HCs were excluded when they were diagnosed with dyslexia, other pain conditions, and any conditions that might influence cognitive or verbal abilities (ie, stroke and brain injury). In addition, HCs were excluded from participation if they had (ever) been diagnosed with a psychiatric disorder including clinical depression and panic/ anxiety disorder. Because of the high comorbidity between FM and mood and anxiety disorders, ${ }^{18,35,42}$ this extra criterion did not apply to the FM group. The study protocol was approved by the Social and Societal Ethics Committee of KU Leuven (registration number: G-2015 03 197). Patients with FM were recruited through patient organizations and from pain clinics in the Limburg region (Belgium), and HCs were recruited through local advertisement. All participants provided written informed consent. Table 1 shows detailed demographic information and clinical characteristics of patients with $\mathrm{FM}$ and $\mathrm{HC}$.

\subsection{Stimulus material}

Informed by multidisciplinary discussions and reviewing the literature on illness beliefs in FM, we selected 6 situations that patients viewed as plausible triggers of (increased) pain episodes. Four of these situations captured in 1 single sentence served as the cues or CS during at least one of the experimental phases. These sentences were formulated in the third person with a fictive FM patient, Kim (a gender-neutral name in Dutch) as the subject. The following sentences were used: "Kim was stressed" (emotional distress), "Kim has vacuumed" (activity-based trigger), "Kim slept badly" (physical trigger), and "The weather was bad today" (environmental trigger). These sentences correspond to stimuli $A, B, X$, and $Z$ in the experimental design. Two additional situations were used during the practice phase: stimuli $C$ and D. The following sentences were used: "Kim had a marital dispute" (social trigger) and "Kim has walked the dog" (activity-based trigger). Which stimulus served as $A, B, X$, and $Z$ in the experimental phases or $C$ and $D$ in the practice phase was counterbalanced across participants.

The CSs were presented on a white computer background screen in font type Arial, black font color, and size 20.5. The outcome or US was the text "PAIN" or "NO PAIN" presented in the same font type, color, and size. All stimuli were presented in a blue frame including the rating scale with anchors $0=$ "certainly no pain" and 10 = "certainly pain" at the bottom of the screen (Fig. 1).

\subsection{Outcome measures}

\subsubsection{Pain expectancy judgments}

During the selective learning task, participants indicated their trialby-trial pain expectancy on a continuous rating scale with anchors $0=$ "certainly no pain" and 10 = "certainly pain" presented at the bottom of the screen. During the prerating phase, participants rated whether they expected that the specific situations (CSs) would trigger pain in themselves (ie, assessing a priori beliefs), whereas during the remainder of the experiment, pain expectancy judgments pertained to Kim, a fictive FM patient (ie, assessing learning effects).

\subsubsection{Postexperimental questionnaires}

To thoroughly characterize both groups and describe possible psychological differences between them, all participants filled out a series of questionnaires after completing the experimental task. (1) Pain severity was measured with the Chronic Pain Grade Scale, ${ }^{40}$ which assesses pain intensity and interference because of pain in daily life. Six of 7 items measure pain intensity on a 10point scale ranging from 0 "no pain" to 10 "pain as bad as it could be." In the seventh item, respondents are asked to estimate the number of days in the past 6 months on which pain significantly hindered their daily activities. Combining the pain intensity score and the disability score leads to the classification into 1 of 4 grades of chronic pain: grade I, representing low pain intensity and low disability; grade II, representing high pain intensity but low

\section{Table 1}

Demographic and clinical characteristics for the FM group and the $\mathrm{HC}$ group separately.

\begin{tabular}{|c|c|c|}
\hline & FM group & HC group \\
\hline \multicolumn{3}{|l|}{$\begin{array}{l}\text { Highest education level (FM: } n=25 \text {; HC: } n= \\
27), \%\end{array}$} \\
\hline Primary school & 8 & 0 \\
\hline Vocational secondary education & 28 & 0 \\
\hline Technical secondary education & 28 & 15 \\
\hline General secondary education & 8 & 11 \\
\hline Bachelor's degree & 28 & 55 \\
\hline Master's degree & 0 & 20 \\
\hline \multicolumn{3}{|l|}{ Occupation (FM: $n=25 ; \mathrm{HC}: \mathrm{n}=27$ ), \% } \\
\hline Working & 16 & 92 \\
\hline Studying & 4 & 4 \\
\hline Unemployed/invalidity/retired & 80 & 4 \\
\hline \multicolumn{3}{|l|}{ Type of medication (FM: $n=26), \%$} \\
\hline Antidepressants & 58 & - \\
\hline Benzodiazepines & 31 & - \\
\hline Opioids & 42 & - \\
\hline Paracetamol & 50 & \\
\hline NSAID & 27 & - \\
\hline Other & 31 & - \\
\hline $\begin{array}{l}\text { Pain treatment (yes-no) (FM: } n=25 ; \mathrm{HC} \text { : } \\
n=27), \%\end{array}$ & 92 & 4 \\
\hline $\begin{array}{l}\text { Medication (yes-no) (FM: } n=25 ; \mathrm{HC} \text { : } \\
\quad n=27), \%\end{array}$ & 96 & 18 \\
\hline
\end{tabular}

Other medication includes muscle relaxants, antipsychotics, and beta-blockers. Assessment of the education level, occupation and pain treatment and medication (yes/no) was part of the web survey including the postexperimental questionnaires, 2 patients failed to fill out this survey. We failed to collect the medication use details from 1 patient; no such data were collected for the healthy controls.

FM, fibromyalgia; HC, healthy control; NSAID, nonsteroidal anti-inflammatory drugs. 


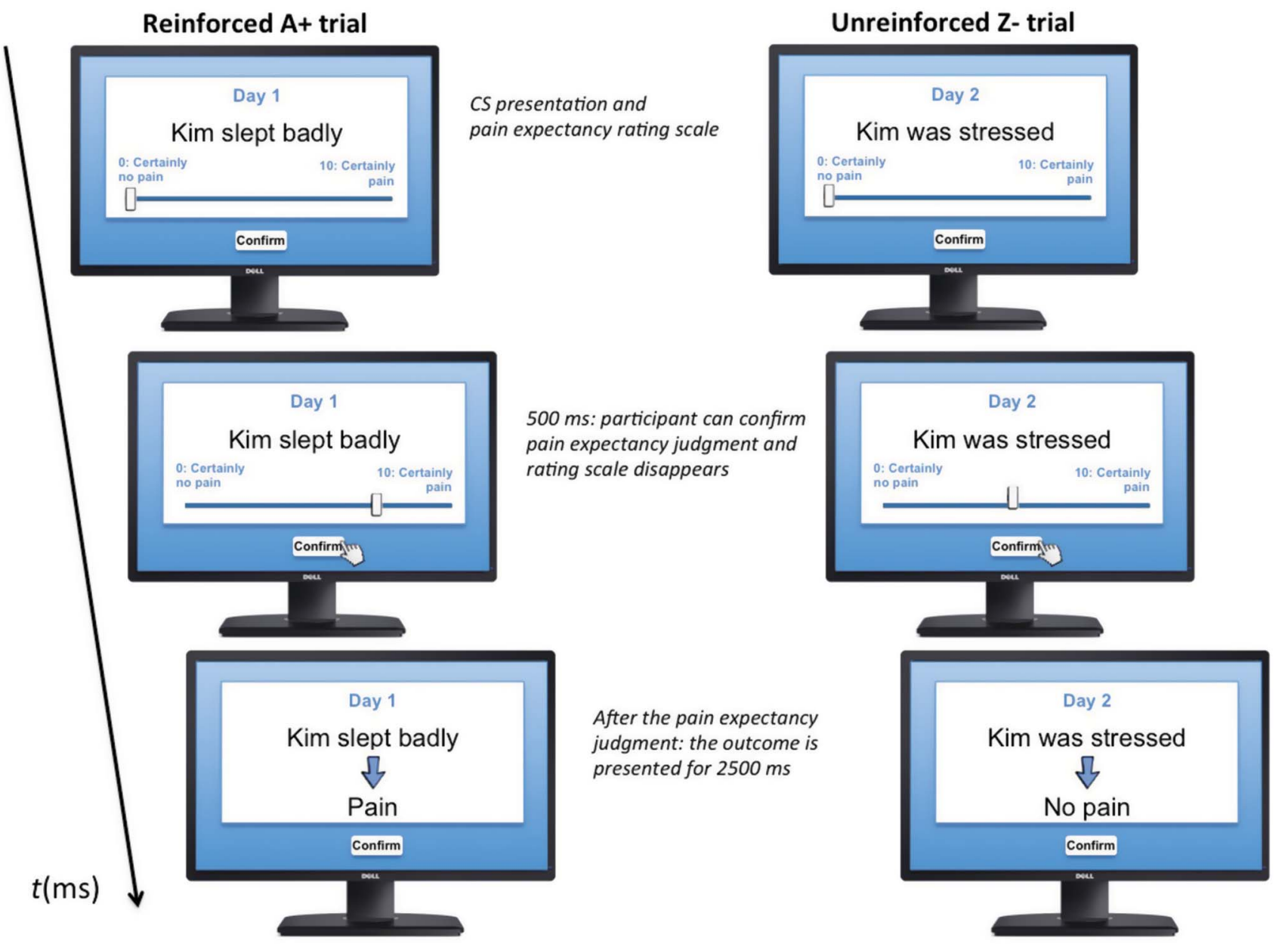

Figure 1. Schematic overview of the experimental task and trial timing during an exemplary A+ and Z- trial during the elemental acquisition phase. CS, conditioned stimulus.

disability; grade III, representing high disability that is moderately limiting; and grade IV, representing high disability that is severely limiting. (2) Pain cognitions were measured with the Pain Cognition List. ${ }^{36}$ The Pain Cognition List consists of 5 subscales: Limitations, Catastrophizing, Internal control, Trust, and Optimism. (3) Fear of movement was measured with the Tampa Scale of Kinesiophobia, ${ }^{31}$ which consists of 17 items evaluating fear of movement and fear of (re)injury. (4) Pain disability was measured with the Fibromyalgia Impact Questionnaire, ${ }^{4}$ which assesses functional status of patients with FM. The total score ranges from 0 to 100 , with 0 indicating no functional interference at all and 100 severe impact of FM on daily functioning. (5) Positive and negative affectivity were measured with the trait version of the Positive and Negative Affect Schedule. ${ }^{11,41}$ Participants indicate to what extent they experience 10 negative and 10 positive emotions in their normal daily life. (6) Anxiety and depression were assessed with the Hospital Anxiety and Depression Scale. ${ }^{34,44}$ (7) Fear of pain was measured with the Fear of Pain Questionnaire, ${ }^{22,32}$ which assesses pain-related fear and anxiety. (8) Attentional control and attentional shifting were measured with the Attentional Control Scale. ${ }^{8}$

\subsection{Protocol}

The selective learning task was programmed in JavaScript, and presented in HTML and CSS supported by a standard web browser. The postexperimental questionnaires were completed using a web survey tool (https://www.limesurvey.org). The experiment lasted approximately 15 minutes and the completion of the postexperimental questionnaires lasted approximately 10 minutes. Participants were allowed to take a break between both parts of the experiment. Data collection took place online; participants completed the task at home on their own computer. During a screening interview and verbal explanation of the study background and aims through telephone, we emphasized the importance of completing the task alone without any help from others, and preferably in a quiet environment. All the participants confirmed that they understood the importance of a quiet and solitary data collection environment and agreed to make every effort to comply with this request. Next, participants received an email with the written information recapturing the research aims, task requirement, and estimated time to complete the online task. The email also contained the informed consent form (which they could sign by replying to the email with the statement "read and approved") and 2 web links: 1 to start the experimental task and 1 to start the postexperimental survey.

\subsection{Selective learning task}

In a between-subjects scenario contingency learning task using a blocking procedure, both patients with FM and HCs were presented with consecutive pages taken from the diary (CSs) of 
Table 2

\section{Experimental design.}

\begin{tabular}{cllll}
\hline $\begin{array}{l}\text { Prerating } \\
\text { phase }\end{array}$ & $\begin{array}{l}\text { Practice } \\
\text { phase }\end{array}$ & $\begin{array}{l}\text { Elemental } \\
\text { acquisition phase }\end{array}$ & $\begin{array}{l}\text { Compound } \\
\text { acquisition phase }\end{array}$ & $\begin{array}{l}\text { Test } \\
\text { phase }\end{array}$ \\
\hline $\mathrm{A}^{*}$ & $\mathrm{C}+$ & $6 \mathrm{~A}+$ & $6 \mathrm{~B}+$ & $\mathrm{X}$ \\
\hline $\mathrm{B}^{*}$ & $\mathrm{D}-$ & $6 \mathrm{Z}-$ & $6 \mathrm{AX}+$ & $\mathrm{B}$ \\
\hline $\mathrm{X}^{*}$ & & & $6 \mathrm{Z}-$ & $\mathrm{Z}$ \\
\hline
\end{tabular}

$Z^{*}$

During each phase, stimuli were presented in a random order. The following sentences: "Kim was stressed," "Kim has vacuumed," "Kim slept badly," and "The weather was bad today" were used as A, B, X, and Z and counterbalanced across participants. "**" refers to the use of the second person as a reference instead of the third person (being Kim) during the prerating phase; no outcomes were presented during this phase. Two additional sentences were used during the practice phase: stimuli C and D ("Kim had a marital dispute" and "Kim has walked the dog"). "+" indicates that the "PAIN" outcome is presented after the stimulus; "-" indicates that the "NO PAIN" outcome is presented after the stimulus. During the test phase, the usual outcomes are not presented, but X, B, and Z are followed by this statement "The diary does not say whether Kim had pain or not' (ie, unreinforced test).

Kim, a fictive FM patient. They were instructed that it was their task to predict whether this fictive FM patient would feel pain in the aftermath of the described diary situations. The pain expectancy rating scale was displayed on the screen together with each CS (Fig. 1). Using the mouse, participants could indicate their pain expectancy by moving a slider on the rating scale. The pain expectancy rating was registered when the participant clicked on the "confirm" button below the rating scale. They could only confirm that their answer after the stimulus was presented for $500 \mathrm{~ms}$. When the participant confirmed his/her pain expectancy judgment, the CS and the rating scale disappeared, and the outcome ("PAIN" or "NO PAIN") was displayed on the screen for 2.5 seconds. A new trial commenced after an intertrial interval of 1.5 seconds during which the computer screen was blank. Blocking was primarily evaluated using the pain expectancy judgment for each CS situation. The experiment consisted of 5 phases that will be described in more detail below: the prerating phase, the practice phase, the elemental acquisition phase, the compound acquisition phase, and the test phase (Table 2).

\subsubsection{Prerating phase}

Before the onset of the experiment, we assessed participants' a priori beliefs as to whether CSs are considered plausible precursors of pain. Participants rated A, B, X, and Z; these stimuli were now presented in the second person referring to themselves instead of the third person referring to the fictive FM patient. The following sentences were presented 1 time each: "You were stressed," "You had vacuumed," "You slept badly," and "The weather was bad today." The presentation order of the stimuli was randomized across participants. Participants indicated their pain expectancy for each situation on a continuous rating scale with anchors 0 = "certainly no pain" and 10 = "certainly pain." No outcome was presented after these 4 prerating trials.

\subsubsection{Practice phase}

During this phase, the participants practiced the use of the rating scale and how to interpret the outcomes. For this purpose, 2 other stimuli C and D were used: "Kim had a marital dispute" and "Kim has walked the dog." These stimuli did not appear in the remainder of the experiment. After participants gave their pain expectancy judgment for stimulus C, the outcome "PAIN" was presented for 2.5 seconds (exemplary of a CS+ trial). An orange frame with the clarifying text "Kim reports that this activity led to pain" accompanied the outcome. Then, an intertrial interval of 1.5 seconds was inserted before the following stimulus was presented on the screen. After participants gave their pain expectancy judgment for stimulus D, the outcome "NO PAIN" was presented for 2.5 seconds (exemplary of a CS - trial). An orange frame with the clarifying text "Kim reports that this activity led to no pain" accompanied the outcome. The presentation order of the 2 practice trials was randomized and which of both stimuli served as the CS+ was counterbalanced across participants. Such clarifying messages were only presented during the practice phase to ensure that participants understood the meaning of the respective outcomes. After the practice phase and before the instructions of the elemental training phase were presented the screen cleared for 3 seconds.

\subsubsection{Elemental acquisition phase}

During this phase, differential conditioning was established using 2 stimuli (A and Z): A was consistently followed by the "PAIN" outcome (CS+) and Z was consistently followed by the "NO PAIN" outcome (CS-). As described earlier, in this contingency learning task, each CS is presented as a transcript of the diary of Kim, a fictive FM patient. Participants were explicitly informed that certain situations may occur several times in the diary. They were also told that, to keep track of the situation, each CS would be presented together with the word "Day" positioned on top of the screen, accompanied by a number starting at 1 and increasing each trial (eg, day 1 for trial 1 etc.). This phase consisted of 12 trials: $6 \mathrm{~A}+$ trials and $6 \mathrm{Z}-$ trials, presented in a randomized order.

\subsubsection{Compound acquisition phase}

During this phase, a novel stimulus B was consistently followed by the "PAIN" outcome (CS+) and Z was still consistently followed by the "NO PAIN" outcome (CS-). In addition, the compound stimulus $A X$ (ie, $A$ and $X$ presented concurrently on the screen) was also consistently followed by the "PAIN" outcome (CS+). Because during the elemental phase, participants have learned that stimulus A suffices to predict the "PAIN" outcome, stimulus $X$ is redundant and learning about this stimulus is expected to be blocked. Therefore, $X$ is referred to as the blocked stimulus. This phase consisted of 18 trials: $6 \mathrm{~B}+$ trials, $6 \mathrm{Z}-$ trials, and $6 \mathrm{AX}+$ trials, presented in a randomized order.

\subsubsection{Test phase}

The crucial test comprised 3 trials: 1 single presentation of $B$, $Z$, and $X$, in a randomized order. These trials were not followed by the usual "PAIN" or "NO PAIN" outcomes, but instead participants received the message that "The diary does not say whether Kim had pain or not." This method of unreinforced testing was used in order not to contaminate the subsequent test trials.

\section{Results}

We performed multiple repeated-measures (RM) analysis of variances (ANOVAs) to evaluate potential differences in elemental acquisition, compound acquisition, and blocking between patients with FM and HCs. Our main dependent variables were pain expectancy judgments for stimuli $B$ and $X$ at test. The Greenhouse-Geisser procedure was used in case the sphericity assumption was violated (corrected $P$ values are reported with 
uncorrected degrees of freedom, together with $\varepsilon$ ). For $\mathrm{X}$, the data distributions showed slight deviations from normality, but the ANOVA procedure has been shown robust to these violationsat least given a moderate sample size. ${ }^{12}$ The data were further analyzed using planned comparisons testing our clear-cut a priori hypotheses. The effect size $\eta_{p}^{2}$ is reported for all omnibus ANOVA effects. All statistical analyses were performed using Statistica 13.1 software (Tulsa, OK).

\subsection{Differences in a priori beliefs between patients and healthy controls}

To evaluate potential preexisting differences between the stimuli before the learning task, we conducted an RM ANOVA with Stimulus Type (A, B, X, and Z) as a within-subjects variable and Group as a between-subjects variable on the pain expectancy judgments during the prerating phase. This analysis yielded a main effect of Group, $F(1,52)=345.85, P<0.001, \eta_{p}^{2}=0.87$. The main effect of Stimulus Type and the interaction were not significant, both Fs $<1$. These results elucidate a clear dissociation in a priori beliefs regarding the stimuli between the patients with FM and the HCs (Fig. 2). The patients with FM reported to expect experiencing pain themselves in all the situations that we used as stimuli in the selective learning task, whereas the HCs overall gave low pain expectancy ratings, indicating that they believed that these situations would not lead to pain for themselves.

\subsection{Selective learning task}

To test for acquisition in the pain expectancy judgments, we conducted a $2 \times 2 \times 6$ RM ANOVA including Group (HC/FM) as between-subjects variable and Trial (1-6) and Stimulus Type (A+ /Z-) as within-subjects variables. The analysis yielded significant main effects of Stimulus Type, $\mathrm{F}(1,52)=96.99, P<0.001, \eta_{p}^{2}=$ 0.65, Trial, $\mathrm{F}(5,260)=4.94, P<0.001, \varepsilon=0.79, \eta_{p}^{2}=0.09$, and Group, $F(1,52)=44.92, P<0.001, \quad \eta_{p}^{2}=0.46$; the latter indicating that the FM group gave overall higher pain expectancy judgments than the $\mathrm{HC}$ group. As expected, the Stimulus Type $\times$ Trial interaction was significant, $\mathrm{F}(5,260)=31.21, P<0.001, \varepsilon=$ 0.66, $\eta_{p}^{2}=0.38$, showing that pain expectancy judgments evolved differently for $\mathrm{A}+$ and $\mathrm{Z}-$ over time. This interaction was not modulated by Group, $\mathrm{F}(5,260)=1.03, P=0.40, \varepsilon=0.66$, suggesting that differential acquisition materialized to the same extent in both groups. Mean pain expectancy judgments for each stimulus type are displayed separately for the elemental and the compound phase in Figure 3A. Follow-up within-group planned contrasts confirmed that no preexisting differences were present between $\mathrm{A}+$ and $\mathrm{Z}$ - during the first trial of acquisition neither in the FM group nor in the $\mathrm{HC}$ group, both $\mathrm{Fs}<1$. However, at the end of the elemental acquisition phase, pain expectancy judgments were higher for $\mathrm{A}+$ compared with $\mathrm{Z}-$, both in the FM group, $F(1,52)=70.57, P<0.001$, and the $\mathrm{HC}$ group, $F(1,52)=$ 37.13, $P<0.001$.

A similar analysis, that is, a $2 \times 3 \times 6$ RM ANOVA including Group (HC/FM) as between-subjects variable and Trial (1-6) and Stimulus Type $(B+/ Z-/ A X+)$ as within-subjects variables, was performed to evaluate differential learning effects in pain expectancy judgments in the compound acquisition phase. The analysis showed significant main effects of Stimulus Type, $F(2$, $104)=117.85, P<0.001, \varepsilon=0.77, \eta_{p}^{2}=0.69$, Trial, $F(5,260)=$ 4.26, $P<0.01, \varepsilon=0.65, \eta_{p}^{2}=0.08$, and Group, $F(1,52)=$ 41.86, $P<0.001, \eta_{p}^{2}=0.45$. Again, patients with $F M$ gave overall higher pain expectancy ratings than the $\mathrm{HC}$ group, irrespective of stimulus type (Fig. 3A). The Stimulus Type $\times$ Trial interaction was significant, $\mathrm{F}(10,520)=4.39, P<0.001, \varepsilon=$ 0.55, $\eta_{p}^{2}=0.08$, showing that pain expectancy judgments evolved differently for $\mathrm{AX}+, \mathrm{B}+$, and $\mathrm{Z}$ - over time. Group status did not modulate this interaction, $F<1$. Follow-up within-group planned contrasts confirmed that at the end of the compound acquisition training, pain expectancy judgments were higher for $\mathrm{AX}+$ and $\mathrm{B}+$ compared with $\mathrm{Z}-$ in the FM group, $\mathrm{F}(1,52)=$ $71.48, P<0.001$, as well as in the HC group, $F(1,52)=48.12$, $P<0.001$.

To test our main hypothesis of selective learning, we performed a $2 \times 3$ RM ANOVA including Group (HC/FM) as betweensubjects variable and Stimulus Type $(B / Z / X)$ as within-subjects variables on the pain expectancy judgments in the test phase. This analysis revealed significant main effects for Group, $F(1,52)$ $=37.65, P<0.001, \eta_{p}^{2}=0.42$, and Stimulus Type, $F(2,104)=$ 65.14, $P<0.001, \varepsilon=0.87, \eta_{p}^{2}=0.56$. The Stimulus Type $\times$ Group interaction was significant, $F(2,104)=4.10, P<0.05, \varepsilon=$ 0.87, $\eta_{p}^{2}=0.07$. Follow-up within-group planned contrasts confirmed that pain expectancy judgments for $B$ were higher than those for $\mathrm{X}$ in the $\mathrm{HC}$ group, $\mathrm{F}(1,52)=10.38, P<0.01$, but not in the FM group, $F(1,52)=2.50, P=0.12$ (Fig. 3B). The betweengroup contrast comparing the difference between $B$ and $X$ between the FM group and the $\mathrm{HC}$ group, however, was not significant, $F(1,52)=1.35, P=0.25$. Taken together, these results at least provide partial evidence for a blocking effect in the $\mathrm{HC}$ group, but not in the FM group.

\subsection{Relationship between a priori beliefs and selective learning}

To explore the relationship between a priori beliefs regarding the test stimulus $(X)$ and the blocking effect, we calculated nonparametric Spearman rank correlation coefficients between the expectancy judgments for $X$ during the prerating phase and the magnitude of the blocking effect (B-X at test) for both groups

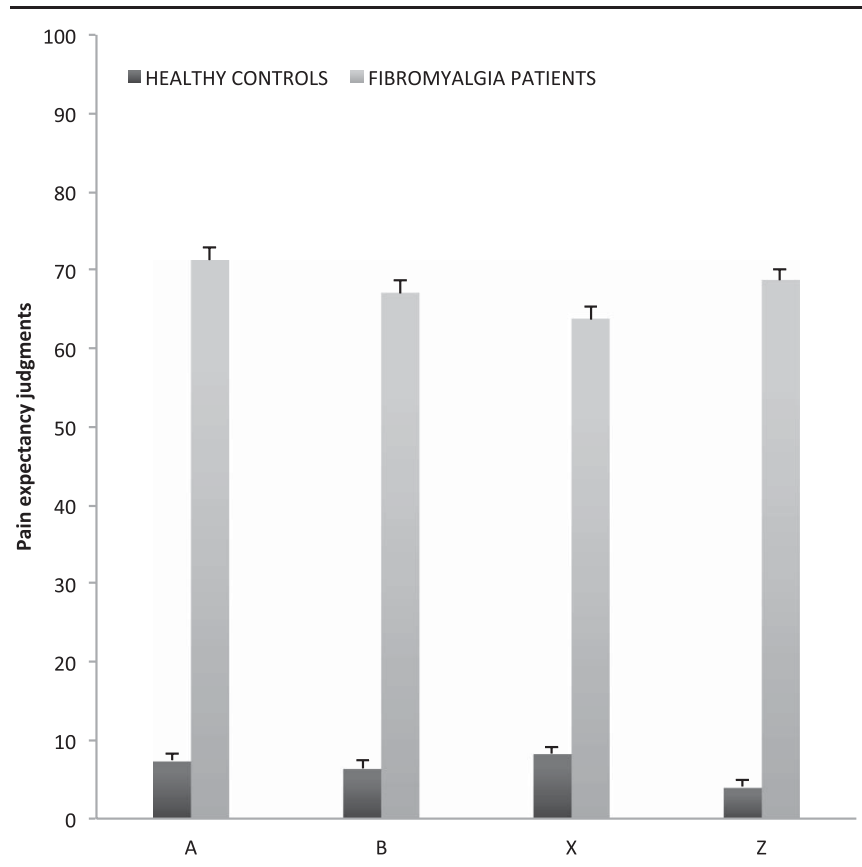

Figure 2. Mean pain expectancy judgments for the unreinforced stimuli $A, B, X$, and $Z$ during the prerating phase for the patients with fibromyalgia and the healthy controls separately. During this phase, the stimuli were presented in the second person (referring to themselves) not in the third person (referring to a fictive fibromyalgia patient). 


\section{A. Elemental and compound acquisition phase}

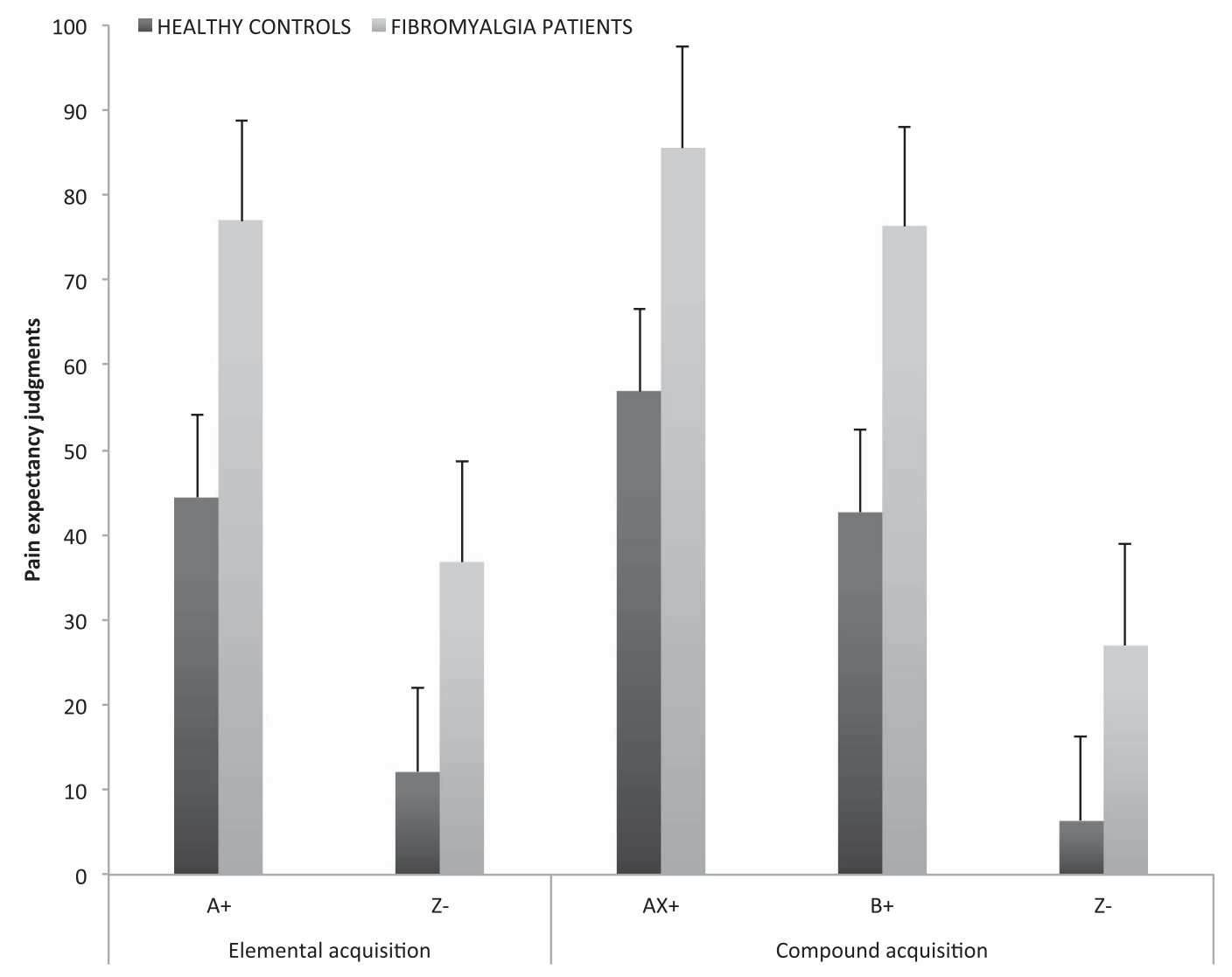

\section{B. Test phase}

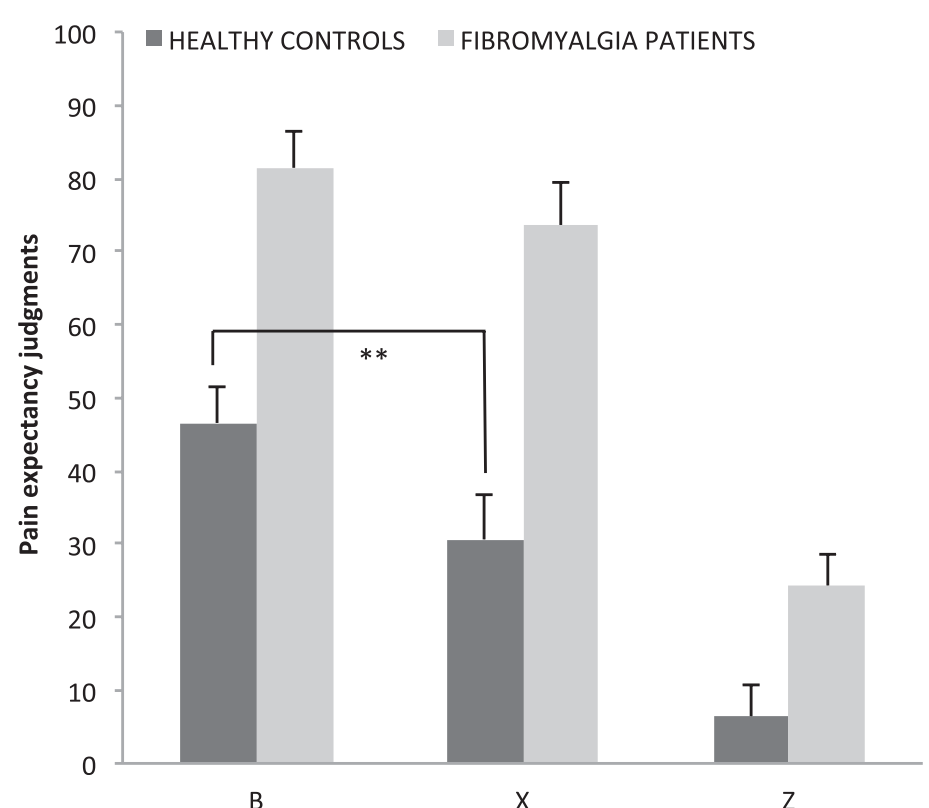

Figure 3. Mean pain expectancy judgments separately for the patients with fibromyalgia and the healthy controls (A) during the elemental and compound acquisition phases for stimuli $\mathrm{A}+, \mathrm{B}+, \mathrm{AX}+$, and $\mathrm{Z}$, and $(\mathrm{B})$ during the test phase for the unreinforced stimuli $\mathrm{B}, \mathrm{X}$, and $\mathrm{Z}$. ${ }^{\star \star} P<0.01$.

separately. A nonparametric correlational analysis was conducted because the preratings of $X$ were not normally distributed. The correlational analysis showed that preratings of $X$ and magnitude of the blocking effect (B-X at test) were not correlated in the FM group ( $\left.\rho_{\text {(pre-rating } X, B-X \text { at test) }}=-0.35, P=0.08\right)$ nor in the HC group ( $\rho_{\text {(pre-rating } X, B-X \text { at test })}=0.21, P=0.29$ ). 


\subsection{Postexperimental questionnaires}

Two patients with FM failed to complete the questionnaires. The final sample size included for the analyses on the postexperimental questionnaires was 52. As expected, there were significant differences between patients with $\mathrm{FM}$ and $\mathrm{HC}$ on most of the included questionnaires (Table 3).

\section{Discussion}

Increasing evidence suggests that patients with chronic pain display impaired differential learning and excessive generalization in pain-relevant fear-conditioning paradigms as well as in basic contingency learning tasks. ${ }^{15,23-25}$ These findings point towards a lack of selectivity. Yet, the litmus test for selective learning effects is the blocking procedure. ${ }^{7,17}$ This study is innovative in directly assessing differences in selective learning between patients with FM and HCs using such a blocking procedure. We introduced a novel selective learning task based around a clinical diary scenario. Participants rated on a trial-by-trial basis whether they expected certain situations (CSs) in the diary of a fictive FM patient would trigger pain (US) in that patient. The procedure did not involve any experimental pain induction, but the verbal outcomes "pain" or "no pain" followed the CS+ and CS-, respectively. We hypothesized that patients with FM would show less blocking than the HCs, indicated by a smaller difference in pain expectancy judgments between the blocked stimulus $(X)$ and the $\mathrm{CS}+(\mathrm{B})$.
First, during acquisition, both groups successfully learned to differentiate between the $\mathrm{CS}+(\mathrm{A}$ and $\mathrm{B})$ and the $\mathrm{CS}-(\mathrm{Z})$. That is, participants in both groups rated their pain expectancy for $A+$ higher than that for $Z$ - during the elemental acquisition phase; they also gave higher ratings for $B+$ and $A X+$ than $Z-$ during the compound acquisition phase. There was no difference in differential learning between patients with FM and HCs. This corroborates earlier findings by Meulders et al. ${ }^{24,25}$ demonstrating in a voluntary joystick movement paradigm, in which 1 movement (CS+) was consistently followed by a noxious electrocutaneous stimulus and another movement (CS-) was not, that patients with FM acquired differential fear of movement-related pain to the same extent as the HC group, albeit slower. These findings, however, contradict those of Jenewein et al. ${ }^{15}$ showing learning deficits in patients with FM compared with patients with osteoarthritis and $\mathrm{HC}$ in a differential fear-conditioning paradigm using geometrical figures as CSs and a painful heat stimulus as US. In their study, 1 CS + was followed by a painful hightemperature stimulus in $50 \%$ of the trials, and by a nonpainful lowtemperature stimulus in the other $50 \%$ of the trials, whereas the CS- was always followed by the low-temperature stimulus. The partial reinforcement schedule and the relatively short acquisition phase compared with the studies of Meulders et al. ${ }^{24,25}$ may explain this discrepancy. In another study by Meulders et al., ${ }^{23}$ contingency learning using hand pain scenarios was investigated in patients with chronic hand pain. In this study, hand pictures in different postures were used as CSs, with the words "no pain" and "pain" as outcomes. Patients with chronic hand pain showed

Table 3

Questionnaire scores for the fibromyalgia (FM) group and the healthy control (HC) group separately.

\begin{tabular}{|c|c|c|c|c|c|c|}
\hline \multirow[t]{2}{*}{ Total sample $(\mathrm{N}=52)$} & \multicolumn{2}{|c|}{ FM group $(n=25)$} & \multicolumn{2}{|c|}{ HC group $(n=27)$} & \multirow[t]{2}{*}{$\mathbf{t}$} & \multirow[t]{2}{*}{$P$} \\
\hline & Mean & SD & Mean & SD & & \\
\hline CPGS—pain intensity & 68.80 & 9.71 & 23.83 & 17.75 & -11.20 & $<0.0001$ \\
\hline CPGS—pain disability & 69.07 & 12.93 & 13.33 & 18.77 & -12.37 & $<0.0001$ \\
\hline CPGS-no. of days disability & 65.04 & 54.96 & 3.19 & 11.99 & -5.71 & $<0.0001$ \\
\hline PCL_catastrophizing & 52.00 & 14.80 & 27.96 & 8.84 & -7.17 & $<0.0001$ \\
\hline PCL_limitation & 27.64 & 5.08 & 16.89 & 4.49 & -8.10 & $<0.0001$ \\
\hline PCL—optimism & 21.96 & 5.28 & 28.89 & 4.08 & 5.32 & $<0.0001$ \\
\hline PCL_-internal control & 14.72 & 4.01 & 19.74 & 3.32 & 4.93 & $<0.0001$ \\
\hline PCL_trust & 12.16 & 3.13 & 15.56 & 2.36 & 4.44 & $<0.0001$ \\
\hline TSK-total score & 38.88 & 10.13 & 33.19 & 5.82 & -2.51 & $<0.05$ \\
\hline $\mathrm{FIQ}$ —total score & 70.69 & 9.48 & 23.51 & 10.71 & -16.77 & $<0.0001$ \\
\hline PANAS—positive affect & 29.40 & 7.81 & 39.81 & 5.07 & 5.75 & $<0.0001$ \\
\hline PANAS—negative affect & 25.92 & 10.96 & 16.19 & 4.22 & -4.29 & $<0.0001$ \\
\hline HADS—anxiety & 10.36 & 5.48 & 4.63 & 3.36 & 4.58 & $<0.0001$ \\
\hline HADS—depression & 9.04 & 4.27 & 2.30 & 2.33 & 7.14 & $<0.0001$ \\
\hline FPQ_medical pain & 19.32 & 6.00 & 17.96 & 5.94 & -0.82 & 0.417 \\
\hline $\mathrm{FPQ}$-minor pain & 17.16 & 6.85 & 14.44 & 3.48 & -1.82 & 0.074 \\
\hline $\mathrm{FPQ}$ - severe pain & 27.52 & 10.10 & 27.63 & 8.50 & 0.04 & 0.996 \\
\hline FPQ_total score & 64.00 & 19.49 & 60.04 & 15.20 & -0.82 & 0.416 \\
\hline ACS - total score & 46.00 & 11.56 & 56.52 & 7.96 & 3.85 & $<0.001$ \\
\hline
\end{tabular}

Two patients failed to fill out the questionnaires. CPGS, Chronic Pain Grade Scale: pain intensity (item 1-3), pain disability (item 4-6), and days of disability (item 7). Based on the CPGS scales, 0\% (0/25) of the patients with fibromyalgia was classified as grade I (low disability - low intensity), 4\% (1/25) as grade II (low disability - high intensity), 36\% (9/25) as grade III (high disability - moderately limiting), and 60\% (15/25) as grade IV (high disability - severely limiting).

ACS, total score of Attentional Control Scale; CPGS, Chronic Pain Grade Scale; FIQ, total score of Fibromyalgia Impact Questionnaire; FPQ, total score of Fear of Pain Questionnaire: subscales are calculated for medical pain, minor pain, and severe pain; HADS. Hospital Anxiety Depression Scale: subscales are calculated for anxiety and depression; PANAS, Positive and Negative Affect Schedule: subscales are calculated for positive affect and negative affect; PCL, Pain Cognition List: subscales are calculated for catastrophizing, limitation, optimism, internal control, and trust; TSK, total score of Tampa Scale of Kinesiophobia. 
slower and significantly less differential acquisition in pain expectancy judgments than the $\mathrm{HC}$ group. One possible explanation may be that there was a significant generalization component embedded in the acquisition training. That is, the $\mathrm{CS}+$ was a picture of a hand that was always presented in the same posture, but could be presented in 4 different orientations. Consequently, participants needed to learn the predictive value of posture, regardless of orientation and thus generalize pain expectancy across the different orientations. It is possible that patients with chronic pain are slower in integrating this information and working out predictive schemes.

Second, we found at least partial support for our main hypothesis. In particular, the HC subjects, but not the patients with FM, showed a significant difference in pain expectancy judgments in response to $B$ and $X$ at test. This lack of blocking in the patients with FM corroborates our selective learning hypothesis. In contrast to our expectations, however, the crucial Group $\times$ Stimulus Type (B vs X) interaction did not reach significance, which means that replication in a larger sample is warranted before this result can be endorsed. There are several plausible explanations for this nonsignificant interaction. A first explanation relates to the use of maximal outcomes during the elemental acquisition phase of this experiment. Beckers et al. ${ }^{1}$ demonstrated that blocking effects are stronger when submaximal outcomes are used. More specifically, when during the elemental training phase $\mathrm{A}+$ is followed by a submaximal outcome (eg, 5 on a 10-point scale) and $A X+$ during the compound training phase is also followed by this submaximal outcome; then, it becomes quickly clear that $X$ is redundant and has no causal relation to the outcome. By contrast, if outcome maximality (eg, 10 on a 10point scale) is used for both $A+$ and $A X+$, the role of $X$ in causing the outcome remains ambiguous. That is, one cannot evaluate whether $X$ has a causal relationship to the outcome or whether a ceiling effect is at play. In the current study, the outcomes "pain" and "no pain" were used, alluding to an "all or nothing" framing of the outcome, but pain expectancy judgments were given on a scale from 0 to $10(0=$ certainly no pain and $10=$ certainly pain), which may have confused participants. Future research could apply submaximal outcomes during training to determine whether this generates stronger blocking effects, at least in the control group. An alternative explanation concerns the use of verbal labels "pain" and "no pain" as outcomes instead of actual painful stimulation. Increasing the motivational value and salience of the US using a fear-conditioning procedure, may increase the sensitivity to detect group differences. Boddez et al. ${ }^{3}$ were able to reveal differences in selective learning between high and low trait anxious people using such a fearconditioning procedure. It needs to be highlighted, however, that the selective learning task, even without experimental pain induction, was able to differentiate between groups: patients with FM gave overall higher pain expectancy judgments than the HC group (main effect of Group). This implies that the current task has at least some diagnostic validity and taps into an underlying mechanism that differentiates between diagnostic groups. ${ }^{38}$

Some findings deserve further attention. First, as mentioned, patients with FM gave overall higher pain expectancy judgments for both CS+ and CS - than HCs. The behavior expected based on the actual contingencies, however, entails high pain expectancy ratings for the CS+ and low ratings for the CS-. From that point of view, it can be argued that the data pattern of the $\mathrm{HC}$ group is remarkable because they show relatively low ratings for the CS+. One possible explanation may be that they interpret the pain scale in terms of the amount of pain they expect the patient to experience rather than whether or not the patient would feel pain. An alternative explanation may lie in the fact that a priori pain expectancy beliefs of the patients with FM are higher for all CSs than for the HCs. It is plausible that although we explicitly instruct participants not to take their own experiences/expectations about pain into account during the task, that patients' personal history push the pain expectancy judgments to the higher end of the scale. Patients with FM indeed showed an expectancy bias. Yet, this expectancy bias for $X$ (ie, higher preratings for $X$ ) was not associated with less blocking in patients with FM, suggesting that both expectancy biases and impaired selective learning are unique characteristics for chronic pain pathology.

One particular strength of the experimental paradigm used in this study is that it allows us to tap into fundamental mechanisms underlying associative learning, and that it can easily be modified to test other pain populations. Because this experimental procedure is an adaptable and easily applicable method to identify selective learning deficits in different pain populations without the need for experimental pain induction, this method has the potential to boost knowledge progress in fundamental pain research.

Some limitations should be highlighted. First, our sample contained mostly female participants with FM; therefore, the generalization of these results to a male population or other pain conditions at this point is not justified. Nevertheless, we believe that the use of this sample is justifiable; several authors have recommended using female samples because of the higher prevalence of women among chronic pain conditions. ${ }^{13,21}$ Second, the groups also differed in medication use, ${ }^{5,10}$ comorbidity with anxiety, $3,16,19,20$ and depression, which may have impacted learning. These features may be viewed as confounding factors. However, it can be argued that these characteristics are intrinsically related to the clinical profile of patients with chronic pain. In our total sample, correlations between the anxiety and depression scores and the blocking effect $(B-X)$ were calculated and turned out to be weak and nonsignificant (see supplementary Table S1, available online at http://links.Iww.com/PAIN/A551). Therefore, it seems implausible that the observed differences in selective learning are merely due to differences in anxiety or depression. With regard to medication use, we previously argued that it is not likely that the use of medication in the patient group explains all the observed differences between patients and $\mathrm{HC}$ because the different drugs that were used by our patient sample may have opposite effects. ${ }^{24,25}$

To conclude, this study provides direct, yet partial evidence for impaired selective learning in patients with FM using a scenario contingency learning task. We believe that deficits in selective threat appraisal may contribute to the transition from regional musculoskeletal pain to widespread pain through the proliferation of anxiety and expectancy biases. Future research should explore how these deficits can be targeted in cognitive-behavioral treatments.

\section{Conflict of interest statement}

The authors have no conflict of interest to declare.

A. Meulders is a postdoctoral researcher of the Research Foundation Flanders (FWO-Vlaanderen), Belgium, (Grant ID $12 \mathrm{E} 3717 \mathrm{~N}$ ) and is supported by a Vidi grant from the Netherlands Organization for Scientific Research (NWO), the Netherlands (Grant ID 452-17-002). Y. Boddez is supported by an Interuniversity Attraction Poles grant of the Belgian Science Policy Office (P7/33). F. Blanco was supported by a grant of the Spanish Ministry of Economy and Competitiveness (Grant ID PSI201783196-R). This research was also supported by a KU Leuven Research Council grant (Grant ID PF/10/005) and the "Asthenes" long-term structural funding Methusalem grant by the Flemish Government, Belgium. 
The data of this study were presented at the topical session on "Protective responses in chronic pain and how they become maladaptive" at the 38th Annual Scientific meeting of the Canadian Pain Society, Halifax, Nova Scotia, Canada.

\section{Acknowledgments}

The authors thank Evelien De Clippeleer for her assistance in the data collection.

\section{Appendix A. Supplemental digital content}

Supplemental digital content associated with this article can be found online at http://links.Iww.com/PAIN/A551.

\section{Article history:}

Received 6 September 2017

Received in revised form 2 March 2018

Accepted 6 March 2018

Available online 12 March 2018

\section{References}

[1] Beckers T, De Houwer J, Pineno O, Miller RR. Outcome additivity and outcome maximality influence cue competition in human causal learning. J Exp Psychol Learn Mem Cogn 2005;31:238-49.

[2] Boddez Y, De Houwer J, Beckers T. The inferential reasoning theory of causal learning: towards a multi-process propositional account. In: The Oxford Handbook of Causal Reasoning. Oxford, United Kingdom: Oxford University Press, 2017. p. 53.

[3] Boddez Y, Vervliet B, Baeyens F, Lauwers S, Hermans D, Beckers T. Expectancy bias in a selective conditioning procedure: trait anxiety increases the threat value of a blocked stimulus. J Behav Ther Exp Psychiatry 2012;43:832-7.

[4] Burckhardt CS, Clark SR, Bennett RM. The Fibromyalgia Impact Questionnaire: development and validation. J Rheumatol 1991;18:728-33.

[5] Burghardt NS, Bauer EP. Acute and chronic effects of selective serotonin reuptake inhibitor treatment on fear conditioning: implications for underlying fear circuits. Neuroscience 2013;247:253-72.

[6] Craske M, Hermans D, Vansteenwegen D. Fear and Learning. From basic processes to clinical applications. Washington: American Psychological Association, 2006.

[7] De Houwer J, Beckers T. A review of recent developments in research and theories on human contingency learning. Q J Exp Psychol B 2002;55:289-310.

[8] Derryberry D, Reed MA. Anxiety-related attentional biases and their regulation by attentional control. J Abnorm Psychol 2002;111:225-56.

[9] Dickinson A. Contemporary animal learning theory. Cambridge: Cambridge University Press, 1980.

[10] Eippert F, Bingel U, Schoell E, Yacubian J, Büchel C. Blockade of endogenous opioid neurotransmission enhances acquisition of conditioned fear in humans. J Neurosci 2008;28:5465-72.

[11] Engelen U, De Peuter S, Victoir A, Van Diest I, Van Den Bergh O. Verdere validering van de Positive and Negative Affect Schedule (PANAS) en vergelijking van twee Nederlandstalige versies [in Dutch]. Gedrag Gezondheid: Tijdschrift voor Psychol en Gezondheid 2006:34:89-102.

[12] Glass GV, Peckham PD, Sanders JR. Consequences of failure to meet assumptions underlying the fixed effects analyses of variance and covariance. Rev Educ Res 1972;42:237-88.

[13] Greenspan JD, Craft RM, LeResche L, Arendt-Nielsen L, Berkley KJ, Fillingim RB, Gold MS, Holdcroft A, Lautenbacher S, Mayer EA, Mogil JS, Murphy AZ, Traub RJ. Studying sex and gender differences in pain and analgesia: a consensus report. PAIN 2007;132(suppl 1):S26-45.

[14] Grillon C. Associative learning deficits increase symptoms of anxiety in humans. Biol Psychiatry 2002;51:851-8.

[15] Jenewein J, Moergeli H, Sprott H, Honegger D, Brunner L, Ettlin D, Grillon C, Bloch K, Brügger M, Schwegler K, Schumacher S, Hasler G. Fearlearning deficits in subjects with fibromyalgia syndrome? Eur J Pain 2013; 17:1374-84.

[16] Jovanovic T, Kazama A, Bachevalier J, Davis M. Impaired safety signal learning may be a biomarker of PTSD. Neuropharmacology 2012;62:695-704.

[17] Kamin LJ. Predictability, surprise, attention, and conditioning. In Campbell BA and Church RM (Eds.) Punishment and Aversive Behavior. New York: Appleton-Century-Crofts, 1969, p.279-96.
[18] Kurtze N, Svebak S. Fatigue and patterns of pain in fibromyalgia: correlations with anxiety, depression and co-morbidity in a female county sample. Br J Med Psychol 2001;74:523-37.

[19] Lissek S, Rabin S, Heller RE, Lukenbaugh D, Geraci M, Pine DS, Grillon C. Overgeneralization of conditioned fear as a pathogenic marker of panic disorder. Am J Psychiatry 2010;167:47-55.

[20] Lissek S, Rabin SJ, McDowell DJ, Dvir S, Bradford DE, Geraci M, Pine DS, Grillon C. Impaired discriminative fear-conditioning resulting from elevated fear responding to learned safety cues among individuals with panic disorder. Behav Res Ther 2009;47:111-18.

[21] Marcus DA, Deodhar A. Gender and Ethnic Issues. Fibromyalgia. New York: Springer, 2011. pp. 249-58.

[22] McNeil DW, Rainwater AJ. Development of the Fear of Pain Questionnaire-III. J Behav Med 1998;21:389-410.

[23] Meulders A, Harvie DS, Bowering JK, Caragianis S, Vlaeyen JWS, Moseley GL. Contingency learning deficits and generalization in chronic unilateral hand pain patients. J Pain 2014;15:1046-56.

[24] Meulders A, Jans A, Vlaeyen JW. Differences in pain-related fear acquisition and generalization: an experimental study comparing patients with fibromyalgia and healthy controls. PAIN 2015;156:108-22.

[25] Meulders A, Meulders M, Stouten I, De Bie J, Vlaeyen JWS. Extinction of fear generalization: a comparison between fibromyalgia patients and healthy control participants. J Pain 2017;18:79-95.

[26] Mineka S, Zinbarg R. A contemporary learning theory perspective on the etiology of anxiety disorders: it's not what you thought it was. Am Psychol 2006;61:10-26.

[27] Mitchell CJ, De Houwer J, Lovibond PF. The propositional nature of human associative learning. Behav Brain Sci 2009;32:183-98.

[28] Pavlov IP. Conditioned reflexes. London: Oxford University Press, 1927.

[29] Rescorla RA. Pavlovian conditioning. It's not what you think it is. Am Psychol 1988;43:151-60.

[30] Rescorla RA, Wagner AR. A theory of Pavlovian conditioning: variations in the effectiveness of reinforcement and nonreinforcement. In: Black $A H$, Prokasy WF, editors. Classical conditioning II: Current research and theory. New York: Appleton-Century-Crofts, 1972. p. 64-99.

[31] Roelofs J, Goubert L, Peters ML, Vlaeyen JW, Crombez G. The Tampa Scale for Kinesiophobia: further examination of psychometric properties in patients with chronic low back pain and fibromyalgia. Eur J Pain 2004;8:495-502.

[32] Roelofs J, Peters ML, Deutz J, Spijker C, Vlaeyen JW. The Fear of Pain Questionnaire (FPQ): further psychometric examination in a non-clinical sample. PAIN 2005;116:339-46.

[33] Shanks DR, Dickinson A. Associative accounts of causality judgment. In: Bower GH, editor. The psychology of learning and motivation. San Diego: Academic Press, 1987. p. 229-61.

[34] Spinhoven PH, Ormel J, Sloekers PPA, Kempen GlJM, Speckens AEM, Van Hemert AM. A validation study of the Hospital Anxiety and Depression Scale (HADS) in different groups of Dutch subjects. Psychol Med 1997;27:363-70.

[35] Thieme K, Turk DC, Flor H. Comorbid depression and anxiety in fibromyalgia syndrome: relationship to somatic and psychosocial variables. Psychosom Med 2004;66:837-44.

[36] Van Breukelen GJ, Vlaeyen JW. Norming clinical questionnaires with multiple regression: The Pain Cognition List. Psychol Assess 2005;17:336-44.

[37] Vansteenwegen D, Iberico C, Vervliet B, Marescau V, Hermans D. Contextual fear induced by unpredictability in a human fear conditioning preparation is related to the chronic expectation of a threatening US. Biol Psychol 2008;77:39-46.

[38] Vervliet B, Raes F. Criteria of validity in experimental psychopathology: application to models of anxiety and depression. Psychol Med 2013;43: 2241-4.

[39] Vlaeyen JW. Learning to predict and control harmful events: chronic pain and conditioning. PAIN 2015;156(suppl 1):S86-93.

[40] Von Korff M, Ormel J, Keefe FJ, Dworkin SF. Grading the severity of chronic pain. PAIN 1992;50:133-49.

[41] Watson D, Clark LA, Tellegen A. Development and validation of brief measures of positive and negative affect: the PANAS Scales. J Personal Soc Psychol 1988;54:1063-70.

[42] Weir PT, Harlan GA, Nkoy FL, Jones SS, Hegmann KT, Gren LH, Lyon JL. The incidence of fibromyalgia and its associated comorbidities: a populationbased retrospective cohort study based on International Classification of Diseases, 9th Revision codes. J Clin Rheumatol 2006;12:124-8.

[43] Wolfe F, Clauw DJ, Fitzcharles MA, Goldenberg DL, Katz RS, Mease P, Russell AS, Russell IJ, Winfield JB, Yunus MB. The American College of Rheumatology preliminary diagnostic criteria for fibromyalgia and measurement of symptom severity. Arthritis Care Res 2010;62:600-10.

[44] Zigmond AS, Snaith RP. The Hospital Anxiety and Depression Scale. Acta Psychiatr Scand 1983;67:361-70. 